Artículo de investigación

Cuestiones de filosofía

ISSN: 0123-5095

Vol. 2 - No. 19

Julio - dciembre, año 2016

pp. $67-86$

\title{
Argumentos purgativos: la estrategia argumentativa de los escépticos pirrónicos*
}

\author{
Purgative arguments: the argumentative strategy \\ of Phyrronian Skeptics
}

Eduardo Geovo-Almanza**

Universidad Libre. Colombia

Fecha de recepción: 5 de agosto del 2016

Fecha de evaluación: 15 de agosto del 2016

Fecha de aceptación: 19 de octubre del 2016

* Artículo de investigación. Grupo de investigación en Filosofía y Teoría Jurídica Contemporánea

** Universidad Libre; Máster en Filosofía Teórica y Práctica, UNED egeovo@gmail.com 


\title{
Resumen
}

Este escrito se centra en el análisis de las estrategias argumentativas utilizadas por los escépticos pirrónicos, definidas por ellos como purgativas, ya que buscan expulsar las creencias dogmáticas, con la finalidad terapéutica de llevar a la suspensión del juicio y, por ende, a la ataraxia. Se inicia con una breve introducción a la argumentación en Grecia; luego, se muestra la importancia y la radicalidad de la argumentación pirrónica, y se pasa a explicitar las diversas estrategias argumentativas utilizadas por los pirrónicos; se concluye señalando los aspectos problemáticos de dichas estrategias.

Palabras clave: Aporía, Argumentos, Ataraxia, Escépticos pirrónicos, Estrategias argumentativas, Suspensión del juicio.

\begin{abstract}
This article is focused on the analysis of the argumentative strategies used by the Phyrronian Skeptics, defined by them as purgative, since they seek to oust dogmatic beliefs with the therapeutic purpose of the suspension of judgment, thus achieving the state of ataraxia. It begins with a brief introduction to Greek argumentation. Then, the importance and radical nature of Phyrronian argumentation is demonstrated. After this, the different argumentative strategies used by the Phyrronian are specified, and finally the problematic aspects of these strategies are indicated.
\end{abstract}

Key words: Aporia, arguments, ataraxia, Phyrronian Skeptics, argumentative strategies, suspension of judgement 


\section{INTRODUCCIÓN}

Aunque hoy parezca inverosímil afirmar cualquier conexión entre las formas de argumentación jurídica y las argumentaciones filosóficas, en la antigua Grecia la política y las leyes proporcionaron gran parte del vocabulario que los filósofos utilizaron para dar testimonio y poner a prueba ideas o teorías ${ }^{1}$. G.E.R. Lloyd ${ }^{2}$ plantea algunas características que parecen reflejar, y no por casualidad, la situación social y política en la que los filósofos y científicos griegos desarrollaron sus actividades: i) ciertos aspectos del concepto y usos de las pruebas; ii) la manera polémica o antagónica en que se realizaba gran parte del debate tanto intelectual como político; iii) el desarrollo de teorías tanto de la argumentación retórica como demostrativa; iv) el hecho de que, en determinadas circunstancias, se privilegiaba el análisis abstracto de situaciones concretas, y v) lo que la idea de reconsideración radical en filosofía y ciencia debe a las instituciones democráticas. En este sentido, se considera que tanto los estilos de los debates políticos y legales, como la existencia de un público que se enorgullecía de la habilidad para evaluar las pruebas y los argumentos, y el vocabulario que procede de las instituciones legales y democráticas, configuraron, en cierta medida, una base para el desarrollo de la argumentación filosófica griega.

Lo anterior indica claramente que la argumentación era una práctica intelectual que desde hace mucho tiempo atrás constituía la esencia de la vida social en Grecia. Como acertadamente lo señala Vegetti, la Historia de la Guerra del Peloponeso, de Tucídides (y, tras ella, las Helénicas, de Jenofonte), da testimonio de los discursos contrapuestos que brindan documentos memorables de aquellas discusiones públicas (2012, pp. 200, ss.). El mismo procedimiento se seguía en la práctica judicial, en la cual se contraponían, por turnos, dos discursos de la acusación y dos de la defensa. La sofística extiende esta práctica social, transformándola en una técnica antilógica de argumentación para tesis contrapuestas; llevada al extremo, dicha forma de argumentación dio lugar a la erística, una técnica capaz de refutar

1 A modos de ejemplos se podría señalar que entre los términos utilizados para la atestiguación o comprobación, elenchos o elenchein, tienen como sentidos primarios: el examen de los testigos o de la declaración de la parte contraria. Una de las expresiones más corrientes utilizadas en los textos filosóficos o científicos para pedir explicación de una proposición es "logon didonaí", literalmente, "dar cuentas", que también tiene un uso técnico particular relacionado con rendir cuentas en el terreno financiero o someterse a una auditoría.

2 Lloyd, G.E.R. Democracia, filosofía y ciencia en la antigua Grecia. En John Dunn (ed.) (1995). 
cualquier afirmación a toda costa; sin embargo, en la sociedad ateniense de los siglos v y IV a.C. la discusión antilógica se había extendido, desde la práctica judicial y política, a todas las formas de disputa cultural. Los médicos disputaban entre ellos y con los detractores de su saber en públicas discusiones de ese tipo, como atestiguan muchos escritos del Corpus hippocraticum. Aristóteles dedicó uno de sus tratados más extensos, Tópicos, a reglamentar de forma racional la discusión antilógica.

Por otra parte, si bien es en Parménides donde por primera vez hallamos argumentos filosóficos propiamente dichos, al concebir la posibilidad de llevar a término una argumentación a partir de principios en apariencia indiscutibles y por medio de deducciones en apariencia rigurosas, con Sócrates se da un giro fundamental al incorporar el diálogo, bajo la estructura de preguntas y respuestas, como forma genuina de argumentación filosófica. A Sócrates, tal y como lo presenta Platón, no le preocupaba la ciencia pura, ni el saber técnico, sino exclusivamente la claridad sobre sí mismo, el poder rendir cuentas y responder, es decir, la disposición a fundamentar (logon didona $)^{3}$.

A diferencia de Parménides, quien representa al filósofo como un iniciado que ha recibido de una diosa el discernimiento de la verdad y denuncia las opiniones comunes como plagadas de errores, para Sócrates el ejercicio filosófico se basa en argumentos y contraargumentos, como también en una disposición a evaluar cualquier argumento venga de donde venga, "con quien sea que encuentre, sea más joven o más anciano, extranjero o conciudadano" (Apol. 30a ${ }^{4}$ ). Platón resume la indagación socrática en una palabra: elenchos, término utilizado para la atestiguación o comprobación, cuyo sentido primario es el de examen de los testigos o de la declaración de la parte contraria, estrategia que considera insuficiente para alcanzar la verdad, porque termina en aporía; por ello propone la dialéctica $\left(\right.$ dialektike $^{5}$ ) como el principal instrumento metódico de su pensamiento, la técnica

3 Expresión utilizada corrientemente en los textos filosóficos o científicos para pedir la explicación de un aserto, que significa literalmente "dar cuenta", el cual también tenía un uso técnico particular relacionado con rendir cuentas en el terreno financiero o someterse a una auditoría.

4 Platón (2005). Apología de Sócrates. Buenos Aires: Eudeba. Traducción, ensayo preliminar y notas de Conrado Eggers Lan.

5 Dialektike es un adjetivo referido al sustantivo techne, "técnica" o "arte", que designa por lo general un "saber hacer"; el adjetivo procede del verbo dialegesthai, que significa, en primer lugar, "dialogar", "discutir". Platón suele emplear la forma sustantivada (to diale gesthai), como sinónimo de dialektike, equivalente a "saber usar el arte de la discusión". 
por excelencia de la indagación filosófica que, al igual que para Platón, se constituía en la manera más genuina de acceso al mundo inteligible y, por ende, a las Formas, ya que era el único modo de elevarse desde lo sensible hacia lo inteligible.

Si bien la refutación socrática (elenchos) podía distinguirse de la antilógica y de la erística de los sofistas por su intención moral y por su deseo filosófico de la verdad, los procedimientos argumentativos de Sócrates no parecían intelectualmente distintos de los empleados por sus adversarios, y estos podían, a su vez, devolverle la acusación de querer imponerse a cualquier precio en la discusión, la philonikía, "... te ufanas de tu victoria, al hacer que sea yo el que responda" (Prot. 360e), incluso de comportarse como un "tramposo" y "malintencionado" (Trasímaco en Rep., I, 340d, 341b) o acusarlo de ufanarse al limitarse meramente a preguntar y refutar cuando se contesta (Rep., I, 336c-d).

Este era precisamente elámbito en el que surge la filosofía helenística y, por ende, la de los escépticos pirrónicos ${ }^{6}$, de la cual se enorgullecía tanto la sociedad agonal griega. Pero a diferencia de las otras escuelas del periodo helenístico (cínicos, estoicos y epicúreos), junto a la Academia y los peripatéticos, lo novedoso de la forma de argumentar de los escépticos pirrónicos es que no buscan la verdad ni lo verosímil,

6 Si bien Victor Brochard divide la doctrina escéptica antigua en tres periodos: escepticismo práctico, escepticismo dialéctico y escepticismo empírico (1945, pp. 52-54), y María Lorenza Chiesara divide el escepticismo griego en tres momentos: los pirronianos, los académicos y los neopirronianos (2007, Índice), en este ensayo se clasifica en dos grupos el escepticismo antiguo: el primero son los pirrónicos, cuyos representantes más significativos son: Pirrón, Enesidemo y Sexto Empírico, y el segundo son los neopirronianos, cuyos representantes son: Arcesilao, Carnéades y Cicerón. Una de las características del primer grupo es, como acertadamente lo señala Bréhier, que Pirrón fue admirado más por su carácter y valor moral que por su doctrina, mientras que Enesidemo y Sexto Empírico se orientaron más hacia lo teórico, lo que denomina "argumentación escéptica técnica" (1956, p. 513). Por otra parte, Luc Brisson sostiene que la denominación "nueva" Academia puede justificarse de diversas maneras. La primera es que a diferencia de la "antigua", cuyos representantes escribían mucho, los de la nueva no escribían, sino que le daban mayor importancia a la enseñanza oral, tomando en parte el ejemplo de Sócrates; la segunda consiste en que, siguiendo el ejemplo de exposición socrática, no imponían sus dogmas, sino que pedían consejos a sus interlocutores y mantenían con ellos vivas conversaciones; es decir, que lo fundamental no era la autoridad del maestro, sino su razón la que debía guiarlos, como también, respondían a las preguntas con nuevas preguntas. Esta manera de comportarse en los diálogos fue propia de Arcesilao, Carnéades y Cicerón. (Brisson, Luc. Sexta Parte. Las tradiciones platónicas y aristotélicas. En: Canto-Sperber, Monique. (2000). Filosofía griega. Vol. 2. La filosofía en la época helenística. Buenos Aires, Docencia, pp. 597-707). 
sino la equivalencia de los discursos, con el fin de suspender el juicio y que, como por azar, les llegue la serenidad de espíritu o paz del alma (ataraxia) en las cosas que dependen de la opinión, que viene a ser el ideal de felicidad del sabio escéptico. En otras palabras, según los pirrónicos, no es la búsqueda de la verdad, sino los contenidos de esta, las certezas o evidencias, lo que se constituye en el principal obstáculo para la felicidad. No hay que olvidar que una de las pretensiones de los escépticos pirrónicos es invitarnos a seguir investigando, donde escéptico se define como aquel que investiga sin conocer el éxito de su indagación (zetética), aquel que suspende el juicio (eféctica) o aquel que no se pronuncia ni en un sentido afirmativo ni en un sentido negativo (aporética) (SE, 1993, I, 3 7-87).

En este ensayo sostengo como tesis que las estrategias argumentativas desarrolladas por los escépticos pirrónicos no solo conducen a una especie de aporía, sino también que la radicalidad de la postura de estos termina volviendo inocua toda argumentación filosófica, ya que al pretender curarnos de todo dogmatismo acaba con uno de los presupuestos centrales de toda discusión filosófica: la búsqueda en común de lo verdadero o el acceso a lo universal.

Lo que no queda claro es el motivo aducido para llevar a cabo la acción terapéutica: "por ser amante de la humanidad", tal vez un reconocimiento del cosmopolitismo que los anima y de la consideración de igual validez de las costumbres, leyes y creencias míticas de los pueblos conocidos en su época. Nussbaum tiene razón cuando afirma que el filósofo pirrónico se ve como un médico compasivo cuyos argumentos podían curar muchos y abundantes tipos de sufrimiento humano, combinando la argumentación detallada, la generalidad y el rigor tradicionalmente buscados por la filosofía con su profundo interés por entender la psicología humana, que los llevó a adoptar complejas estrategias interactivas, retóricas, literarias- concebidas para permitirles hacer frente eficazmente a su objeto de estudio (2003, p. 22).

Ahora bien, dado que los escépticos pirrónicos utilizan diversos tipos de argumentos con una finalidad claramente terapéutica y en concordancia con la actitud zetética que los anima -investigar sin conocer el éxito de su indagación-, no podemos hablar de que adopten unas estrategias argumentativas fijas, como las utilizadas por Sócrates en los diálogos de juventud, ni que sus proposiciones sean verdaderas,

7 En adelante será citado como EP. Empírico, S. (1993). Esbozos Pirrónicos. Madrid: Gredos. Introducción, traducción y notas de Antonio Gallego Cao y Teresa Muñoz Diego. 
ya que no las establecen para aclarar definitivamente las cosas a propósito de las cuales se adoptan, sino de modo aproximativo y, si se quiere, de forma impropia. Es decir, que la importancia de los argumentos recae en el uso que se hace de estos, como medicina del alma, ya que de lo que se trata es de expulsar las creencias dogmáticas; lo paradójico es que también consideran que se expulsa el argumento utilizado: “... pueden refutarse por símismas al estar incluidas entre aquellas sobre las que se enuncian" (EP, I, 206). Consideran, pues, que al desaparecer la creencia desaparece también el argumento que fue utilizado para derrumbar dicha creencia, “... igual que, entre los medicamentos, los purgativos no solo expulsan del cuerpo los humores orgánicos, sino que se expulsan a sí mismos junto con esos humores" (EP, I, 206-207). Es decir, con el fin de evitar la primacía del uno sobre el otro y una vez logrado el propósito, desaparece tanto uno como el otro; en otras palabras, las estrategias argumentativas no son más que formas auxiliares con las cuales controvierten los argumentos dogmáticos.

\section{Argumentos Pirrónicos como purgativos}

Con la pretensión de alejarnos de las creencias dogmáticas y con una finalidad terapéutica, para pasar de una vida dolorosa y frustrada a una vida feliz y serena, los escépticos pirrónicos hicieron uso de diversas estrategias argumentativas. Hay un famoso pasaje en Esbozos Pirrónicos donde Sexto Empírico explicita dicha estrategia, proponiendo una analogía médica: los argumentos que esgrimen sirven como purgativos, en los que no solamente se relativiza la verdad del argumento propuesto por el interlocutor, sino que, como consecuencia de lo anterior, después también desaparecerá el argumento planteado por el escéptico (EP, I, 206-207). No obstante, aunque es evidente que la estrategia argumentativa de los escépticos puede servir como medicina del alma, considero que lo que se busca en realidad con estos argumentos es conducir a situaciones de perplejidad y, por ende, a la suspensión del juicio y a la ataraxia. Sexto Empírico caracteriza dicha orientación aporética como investigar y dudar de todo, al igual que dudar frente a la afirmación y la negación (EP, I, 7). Respuesta que no aclara el sentido que tiene la aporética dentro de la argumentación escéptica, sino que señala unos rasgos que vendrían a ser accidentales, en la medida en que el énfasis no recae tanto en que se pueda dudar de todo, algo que de por sí es problemático porque no dudan de todo, sino que si nos atenemos a la etimología del término, procedente del antiguo griego, significa una cuestión difícil de resolver o de tratamiento inviable, bajo la forma metafórica general de una situación de callejón sin salida (a-póros, sin paso, sin camino a través). En otras palabras, lo que pretenden mostrar los escépticos es 
que al no ser posible conciliar dos o más posiciones o creencias establecidas en un dominio determinado, ya sea de la física, la lógica o la ética, esta situación de perplejidad nos lleva a la conclusión de optar por suspender el juicio (epoché).

En respuesta a las objeciones de que los argumentos escépticos carecen de consistencia y profundidad, Sexto Empírico replica que "el que parte del escepticismo, unas veces se vale de formas de persuasión enérgicas y otras no vacila en plantear adrede argumentos que parecen poco brillantes, porque muchas veces le bastan para alcanzar su propósito" (EP, I, 281); en esta línea, se puede afirmar que formulan aporías con la finalidad de conducir al desconcierto, mas no a la inanición, ya que no abandonan su interés investigativo o por saber cómo son las cosas. Aristóteles, a diferencia de los escépticos, considera que las aporías se presentan solamente en los inicios de una investigación filosófica, como motivo impulsor y directriz del análisis conceptual y de la reconstrucción crítica al abordar un tema o un campo de estudio, definiendo la aporía como el no saber qué hacer o no saber a qué atenerse ante dos razonamientos o argumentos equiparables que discurren en dirección contraria (Metafísica, Libro III, 995a30 y ss.); un problema o situación aporética se asemeja a un nudo, que requiere su conocimiento para encontrar una salida o solución (euporía, euporeín).

Tal parece, entonces, que hay dos posibles maneras de entender la aporía. La tradición aristotélica la entiende como dificultad de carácter conceptual o sustantivo que bien puede motivar una investigación ulterior a superar mediante los razonamientos científicos y, en otros casos, a través de los razonamientos dialécticos; en aquellos dominios en que se enfrentan entre sí opiniones discordantes, un modo de comportarse racionalmente en estos casos es argumentar. Aristóteles caracteriza genéricamente el ámbito de la argumentación como ámbito de la dialéctica; razonamiento dialéctico que se sitúa en el contexto del diálogo, de la discusión, donde se presentan opiniones contrapuestas, ambas susceptibles de ser defendidas y atacadas con argumentos. Pero lo importante para el tema que nos ocupa es que, como bien lo señala Calvo Martínez, el dialéctico sabrá argumentar contra la opinión propuesta por el otro, sometiéndola a prueba y a eventual refutación, pero también sabrá sostener la opinión propia con argumentos, siendo capaz de "no decir nada contradictorio", es decir, evitando ser refutado por caer en contradicción (2008, p. 20).

Los escépticos, por su parte, considerarán que las aporías conducen a situaciones de perplejidad, porque no encuentran razones de peso que los lleve a aceptar uno 
de los argumentos; emplean sus argumentos no para convencer a los otros acerca de la verdad de sus creencias y, menos, con el fin de señalar que es contradictorio, sino para indicar que no es más uno que el otro, que son equivalentes porque discurren paralelamente sobre el tema en cuestión. Me parece, entonces, que el problema es cómo entender la persuasión en los escépticos, al igual que determinar si logran persuadir a los otros acerca del interés de tipo teórico que los lleva a argumentar, al buscar, en primer lugar, la suspensión del juicio y, en segundo lugar, el interés de tipo práctico que los anima: la ataraxia.

Ahora bien, aunque los escépticos se muestran reacios a admitir uno de los argumentos, en el evento en que logren persuadir tendrían que aceptar que, al menos, lo consideran un buen argumento; esto significa estar seguros de que toda persona racional será persuadida por él.

Otro aspecto que quisiera tratar aquí es el de los denominados dobles razonamientos o discursos dobles (Dissoí lógoi), una colección anónima de argumentos cuyo propósito era mostrar que es posible argüir igualmente bien en favor y en contra de cualquier opinión, estructura que fue utilizada por los sofistas porque podría ser vista como semejante a la forma de argumentar de los escépticos pirrónicos. Para Solana Dueso, el principio del escepticismo de Sexto no es más que el principio antilógico de Protágoras (2013, p. 451, n. 2), es decir, sugiere que, si bien no dicen lo mismo, la estructura argumentativa es idéntica. En mi opinión, la semejanza es engañosa, en la medida en que Sexto considera que el fin buscado por los sofistas es de naturaleza erística; aunque prevalece la calificación negativa de argumentos destinados a conseguir el éxito a costa de cualquier valor intelectual o moral, no la distingue de otra subclase que sería la de aquellos que practican la erística por el gusto del argumento; en esto concuerda con Platón, ya que el sofista, al sostener afirmaciones contradictorias que lo llevan a hacer fuerte el argumento débil, se pone del lado de la injusticia, considerando más importante la dialéctica $\left(\mathrm{CP}, \mathrm{II}, 6-7^{8}\right)$.

\section{Estructura de los argumentos Pirrónicos}

$\mathrm{Al}$ argumentar de forma aporética, los escépticos parten del principio de "que a cada proposición se le opone otra proposición de igual validez” (EP, I, 12).

8 Empírico, S. (1997). Contra los profesores. Libros I-VI. Madrid: Gredos. Introducción, traducción y notas de Jorge Bergua Cavero. En adelante CP. 
Es decir, frente a una proposición dogmática, el escéptico plantea otra que sirva de antítesis o de proposición enfrentada, que presente similares características pero que sea opuesta. Lo que sigue es que al determinarse que ninguna de las dos proposiciones enfrentadas aventaja a la otra, en cuanto a su credibilidad o no credibilidad, porque son equivalentes o iguales, se concluye en la suspensión del juicio. Esto significa que el escéptico no se limita únicamente a desarrollar la capacidad de sostener la equivalencia de la proposición creada por él, sino que llega a la conclusión sobre la completa neutralidad de los argumentos, entendiendo por neutralidad el no asentimiento a ninguna de ellas (1993, I, 190). En este caso se hace referencia a proposiciones que guardan relación con cuestiones que atañen a "cosas no manifiestas", que tratan acerca del trípode conceptual (realidad, verdad y bien); ya que no discuten sobre aquellas cosas que imprimen las sensaciones, "que se imponen a su imaginación" porque les resulta evidente y es concordante con su sentir, "sin asegurar nada sobre la realidad exterior" (1993, I, 15).

Pues bien, tal parece que la estrategia argumentativa del escéptico consiste en recalcar que en cualquier discusión filosófica ninguna proposición es más que otra; pero, por más que nos aclaren que esto obedece a que son consideradas igualmente válidas, se podría objetar: ¿en qué redunda que el escéptico considere válida su proposición o que ambas sean igualmente válidas?; ¿ambas son consideradas válidas porque presentan la misma estructura formal o en cuanto al contenido, pero no en la forma, se refleja la misma estructura?; ¿quién o quiénes concluyen que presentan igual validez?: ¿el interlocutor?, ¿los que asisten a la discusión en el ágora?, ¿el escéptico?

Aunque no ha sido tratado lo relativo a la estructura de los argumentos escépticos, se puede sostener que se presentan bajo la forma de discursos contrapuestos; por lo tanto, el escéptico pirrónico enfatizará no en lo común, sino en las diferencias, señalando, además, que el lenguaje monádico resulta insuficiente para dar cuenta de lo tratado, defendiendo la categoría de relación frente a la de sustancia o idea. Pese a que no abandonan el interés cognoscitivo, deciden suspender el juicio y conseguir la ataraxia, con la "esperanza de conservar la serenidad de espíritu" (EP, I, 12). Sin embargo, más allá de aquello a lo que se llega como conclusión, de lo que se trata es de defender lo plural frente a lo monológico, partiendo de la aceptación de la relativización de los juicios.

La estrategia argumentativa de los escépticos pirrónicos adquiere diversas formas. La primera forma consiste en contraponer fenómenos a fenómenos; en este nivel 
primario de conocimiento de las cosas del mundo exterior los contenidos de las percepciones adquieren igual validez, entendida esta como igual credibilidad o incredibilidad. El ejemplo que da Sexto Empírico es: si alguien afirma que desde lejos la torre parece circular, el escéptico expresa que desde cerca la misma torre parece cuadrangular; esto no se limita solamente a la cuestión de la multiplicidad de percepciones que tienen los seres humanos, sino que su reflexión se extiende al reino animal conocido hasta ese momento; observando las diferencias que hay en aquellos órganos encargados de juzgar y de sentir de los distintos animales, podemos concluir que sus representaciones mentales son plurales y contradictorias. En uno de los ejemplos que encontramos en el Primer Tropo, afirma Sexto Empírico que, dado que el color de los ojos de los animales es diferente, "es natural -pienso yo- que les resulte diferente la respectiva percepción de los colores" (EP, I, 4445); este mismo razonamiento se puede utilizar también para los demás sentidos. La generalización del lenguaje relacional se orienta a criticar los argumentos dogmáticos en dos sentidos: primero, no se trata, como en los dogmáticos, de señalar la desvalorización o lo engañoso de las percepciones, sino que debido a que las mismas cosas aparecen de forma diferente a los animales podremos afirmar algo acerca de cómo nos imaginamos los objetos, mas no cómo son en realidad (EP, I, 59); segundo, al incluir en el análisis, además de los hombres, las representaciones de otros animales, se derrumba toda pretensión de considerar como juez al hombre, ya que es imposible que prevalezcan nuestras representaciones mentales sobre la de los demás animales, al igual que las valoraciones o juicios que hagamos (EP, I, 61).

La segunda forma de estrategia argumentativa contrapone consideraciones teóricas a consideraciones teóricas ${ }^{9}$; dicha estrategia consiste en oponer unas veces cada una de estas contra sí misma, y otras, a cada una de las demás (EP, I, 148); para ello, Sexto Empírico toma como base no las percepciones, sino las descripciones empíricas de la diversidad cultural, incluyendo las consideraciones teóricas de otros pueblos y regiones del mundo antiguo, con el fin de señalar que nada es por naturaleza ${ }^{10}$, sino que todo es opinable y relativo; la distinción que introduce en esta estrategia argumentativa no es entre ser y apariencia, sino entre naturaleza y relatividad cultural. Atendiendo a la estructura de los discursos, proposiciones

9 Por consideraciones teóricas se entienden: las formas de pensar, costumbres, leyes, creencias míticas y opiniones dogmáticas (I, 145).

10 Una de las condiciones para que sea algo por naturaleza es que todos tengan la misma valoración del tema tratado o a todos sea evidente tal valoración. 
opuestas, Sexto Empírico amplía, en el Décimo Tropo, su análisis a cuestiones éticas: i) una costumbre a una costumbre: los persas creen que es decoroso usar vestido estampado en flores y que caiga hasta los pies; nosotros, que es indecoroso (EP, I, 148); ii) una forma de pensar a una forma de pensar: Diógenes sostiene una tesis sobre tal cuestión, Aristipo afirma todo lo contrario; iii) las opiniones dogmáticas unas a otras: a unos les parece que existe una única sustancia, y a otros, infinitas (EP, I, 151); iv) una costumbre a una ley: entre los persas es costumbre la homosexualidad masculina, mientras que entre los romanos está prohibida por ley (EP, I, 152); v) una creencia mítica a una costumbre: los mitos dicen que Crono devoraba a sus hijos, siendo costumbre entre nosotros cuidar de los niños; vi) una costumbre a una opinión dogmática: entre nosotros es costumbre pedir mercedes a los dioses, mientras que Epicuro sostiene que la Divinidad no se ocupa de nosotros (EP, I, 155). Sin pretender agotar esta temática, Sexto Empírico concluirá que, debido a la disparidad de opiniones que se presentan, no se puede hablar con objetividad de la realidad, delimitando sus juicios a cómo aparecen o se muestran según las diversas consideraciones teóricas tratadas (EP, I, 163).

Uno de los problemas de lo tratado por Sexto Empírico en este Décimo Tropo es que no se puede hablar de discursos, sino de proposiciones opuestas o enfrentadas, en las que no se encuentran expuestas las razones o proposiciones que sirven de apoyo a una u otra tesis. Son dos tesis que, aunque se parte de que tienen igual validez, es significativo el enunciado que se hace, en uno de ellos, en primera persona (singular o plural), para señalar la diferencia de costumbres de otros pueblos con respecto a la de la polis en la cual vive el escéptico. Me parece que el problema no es tanto plantear que unos tienen por costumbre esto y nosotros tenemos otras costumbres, que para ellos eso está bien mientras que para nosotros eso está mal o viceversa, sino que al enunciar en primera persona de forma absoluta está expresando una opinión favorable a una de las dos tesis. Lo anterior me lleva a sostener que los pirrónicos no mantienen la equivalencia de los opuestos, ya que las consideraciones teóricas se fundamentan en lo que denominan "la observancia de las exigencias vitales" (EP, I, 22), es decir, en la tradición, en lo legado por las leyes y costumbres, en el aprendizaje de las artes, lo cual determina los juicios que se hacen sobre las costumbres de otros pueblos. También queda la pregunta acerca de si se mantendría la misma valoración moral en el caso en que el escéptico se trasladara a vivir a otra ciudad: ¿el nosotros ateniense cambiaría por el nosotros persa? Tal vez cuando hablan de nosotros se refieren a nosotros como seres humanos, ya que el tipo de reflexión que se hace en filosofía se distingue fundamentalmente de la reflexión sobre sí mismo en el sentido de una reflexión 
autobiográfica. Una razón para preferir el "nosotros" al "yo" es que no intenta meramente describir otras culturas, sino que al comenzar en primera persona plural busca aclarar el comprender propio y, en la medida en que entra en contacto con otras culturas, amplía el horizonte propio. No obstante, lo que no se deduce de estos debates es si los escépticos mencionan otras culturas como objetos de curiosidad o, por el contrario, son vistas como interlocutoras en un diálogo imaginario en el que las estructuras de otras culturas se ven como si fueran potencialmente las suyas propias. De ser aceptada la segunda opción cabría la posibilidad de que los escépticos, además de criticar la cultura propia, podrían hacer críticas a las culturas ajenas.

Otro aspecto por considerar es que tal parece que los tropos no son resúmenes de debates sostenidos por los pirrónicos, sino esquemas lógicos elaborados por Enesidemo y Agripa, cuya finalidad es conducir cualquier debate a la suspensión del juicio. Al no ser un resumen de un concurso ni de un debate en el que un árbitro o moderador expone el tema por discutir, y dos oradores desarrollan las posiciones enfrentadas, como es el caso de los dobles razonamientos de los sofistas, se configura en una especie de monólogo que no pasa del nivel descriptivo al conversacional, en el que se observa que el escéptico expone las dos tesis y concluye en la necesidad de la epoché. Sin embargo, como nos recuerda Bilbeny, la Atenas sociológica dista de ser una sociedad monocultural, se caracteriza por ser una ciudad multiétnica, multilingüe y multirracial (1998, pp. 17 y ss.); el interés moral que tanto preocupaba a Sócrates subsiste en la época helenística, ya que no encontramos de los escépticos más allá de meras descripciones de hábitos y costumbres, posibilidades de que se puedan establecer acuerdos en una sociedad multicultural como es descrita Atenas.

En el libro III de Esbozos Pirrónicos es donde se exponen con mayor detalle otros argumentos que tratan sobre aspectos de la filosofía práctica o parte ética de la filosofía (Cap. XXI y ss); en este apartado se investiga acerca de la realidad y naturaleza de lo bueno, lo malo y lo indiferente, tema al cual le dedica gran parte de su análisis en su polémica con los estoicos y otras escuelas rivales; como también se ocupa de temas no tan generales, sino particulares, tales como: sobre la valentía y el placer, sobre lo vergonzoso y lo ilícito, sobre la devoción a los dioses y sobre el culto a los muertos.

La estrategia argumentativa consiste, por lo general, en exponer la tesis escéptica $\mathrm{y}$, en segundo lugar, la tesis dogmática; luego, da paso a presentar otras tesis 
dogmáticas, señalando que no solo no hay unanimidad entre los dogmáticos sobre la existencia objetiva del tema en cuestión, sino que también en el caso en que la hubiera llevarían una vida de turbación y agitación permanente, más que de felicidad. Es decir, debido a que no les reporta ningún beneficio a quienes lo poseen (EP, III, 278), queda como única posibilidad la suspensión del juicio y el alejamiento de la petulancia dogmática (EP, III, 235).

Mi análisis se centra en el segundo tema de indagación: si existe algo bueno por naturaleza (EP, III, 179). La tesis escéptica se resume así: todo lo que por naturaleza produce una sensación la produce de forma parecida en todos los que están en un estado normal; nada de lo que se llama bueno produce a toda la sensación de bueno; conclusión: luego nada es bueno por naturaleza. La tesis dogmática se sintetiza así: los peripatéticos afirman que hay tres tipos de cosas buenas; algunas de ellas son relativas al alma, como las virtudes; otras al cuerpo, como la salud y cosas similares; otras son externas, como los amigos, la riqueza y cosas análogas. Presenta otra tesis dogmática, la de los estoicos, quienes también consideran que hay un triple género de cosas buenas; algunas son relativas al alma; otras externas, como el hombre honesto y el amigo, y otras ni relativas al alma ni externas, como el honesto consigo mismo. Se diferencian de los peripatéticos en las cosas relativas al cuerpo y las cosas externas (EP, III, 180-182). Otras tesis las encontramos en los epicúreos, quienes aceptan el placer como algo bueno, mientras que otros dicen que es claramente malo. Al no ser posible dar crédito ni a todas ni a ninguna de estas posturas, se concluye en la suspensión del juicio, ya que no se puede asegurar qué es lo bueno por naturaleza.

Por mucho que Sexto Empírico pretenda presentar los argumentos como equivalentes, con el fin de señalar que "nada es más" (ou mallon), como fórmula para sostener que una cosa no es más que otra, esto no se logra, en mi opinión, debido a que los argumentos versan sobre cuestiones diferentes. La postura escéptica se orienta hacia la negación de lo bueno, que no es por naturaleza, sino que es algo relativo ${ }^{11}$, mientras que la de los dogmáticos consiste en tratar acerca

11 Si bien en diferentes apartados Sexto Empírico utiliza esta noción para tratar las cuestiones morales de lo relativo como un juicio subjetivo, cuyas expresiones no se presentan de forma absoluta, sino con relación a algo, en otras partes también habla de contrato y de convención. Por ejemplo, en Esbozos Pirrónicos define la ley como un contrato escrito entre los que forman un Estado, mientras que la costumbre es la aceptación común de alguna cosa por muchos hombres, es algo convencional (I, 146). No obstante, en Contra 
de los bienes externos, del cuerpo y del alma, sobre todo la virtud, que conducen al bien supremo, como es caracterizada la felicidad por los peripatéticos y los estoicos; finalidad en la cual también concuerdan los pirrónicos cuando afirman que el Bien ${ }^{12}$ es útil, elegible por sí mismo, es envidiable y es capaz de hacer la felicidad (EP, I, 175). Pero las divergencias reaparecen cuando se trata de precisar en qué consiste la felicidad; se podría corregir la tesis escéptica para mostrarla como tesis equivalente a las otras. Por ejemplo, la felicidad se cifra en la serenidad de espíritu o tranquilidad de ánimo y en el control del sufrimiento, lo cual no depende primordialmente de los bienes externos ni del cuerpo y menos del alma, sino de vivir sin creencias y aceptando la falta de sentido del mundo.

Por otra parte, tal parece que una de las críticas de los escépticos a las posturas dogmáticas se centra en que lo bueno no es algo unívoco, porque lo entienden de distinta manera; pero el problema no es solo la divergencia de opiniones, sino que, en el evento en que llegara a ser una sola no sería de ninguna utilidad, debido a la turbación y agitación que generaría el tratar de no perder lo que a esta persona le parece que es bueno por naturaleza (EP, I, 27). Esta es una exigencia de pérdida de credibilidad al no ser algo unívoco por parte de los dogmáticos, además de ser un requisito de tipo lógico, más que algo propio de la filosofía práctica, en la que se da la posibilidad de convencernos mutuamente y de aclararnos aquello sobre lo que tomamos decisiones; consideran lo bueno como un género, como una unidad

los profesores sugiere la idea de la ley como algo inalterable que ha sido corrompida por los retóricos; pone como ejemplo Atenas: "entre quienes permiten la retórica las leyes cambian cada día, así entre los atenienses"; si se pasa fuera tres meses, cuando se regresa, en lo que respecta a las leyes la ciudad ya no es la misma (II, 35-36). Así mismo se encuentran críticas al convencionalismo no solo bajo el criterio de que no hay que dar credibilidad ni a uno ni a muchos, sino también en la medida en que consideran ilusorio adherirse al acuerdo de la mayoría (II, 43); la división de los juicios por la cantidad de gente es inaprehensible; además de la multiplicidad de estados de ánimo de la mayoría, no es posible rastrear los juicios de todos ellos (II, 45). En el aspecto lógico descalifica el principio de inducción, es decir que se pueda garantizar lo universal a partir de los casos particulares (II, 204). Tal parece que en el plano teórico adoptara una postura relativista mas no convencionalista, situación contraria a lo que plantea en lo práctico, en el actuar, porque al reconocer que no le es posible vivir completamente inactivo y donde es poca la importancia que tiene la suspensión del juicio, entiende lo manifiesto o fenoménico como vivir según las costumbres patrias, las leyes, las enseñanzas recibidas y los sentimientos naturales; es decir que acepta la convencionalidad de las costumbres y de las leyes.

12 La diferencia entre el bien en minúscula y el bien con la $\mathrm{B}$ en mayúscula que introduce el intérprete tal vez es con el fin de diferenciar los bienes, las cosas buenas, de lo bueno. 
genérica, más que una unidad de analogía, cuyo bien no sería algo que pudiera realizar y conquistar el hombre, por ser universal y abstracto. Me parece, entonces, que su interés no es ahondar en la deliberación práctica que tiene como meta lo bueno, porque esto les implicaría pasar de lo descriptivo a la racionalidad dialógica; a esto se añade que no se trata de que haya diversas opiniones entre los filósofos y personas corrientes, sino de que en la deliberación se pregunta no solo por las razones que están a favor y en contra de lo que se está diciendo o pensando, sino que se apunta a una comprensión compartida, que se da del hecho de que podamos dialogar los unos a los otros. Esta no es una posibilidad arbitraria, sino una a favor de la cual hay buenas razones, y ello porque, primero, el mero hecho de que nos encontramos en una cierta tradición no basta como horizonte para justificar cómo es bueno vivir; segundo, la manera como los seres humanos se reúnen en agrupaciones sociales se basa en la capacidad de comunicarse sobre lo que consideran bueno para ellos.

La tercera forma de estrategia consiste en contraponer cosas presentes a cosas presentes y cosas presentes a cosas pasadas o futuras. La importancia de este tipo de proposiciones no radica en el tiempo verbal, sino en la manera como introducen la noción de lo probable; esta se da con el fin de negar cualquier posibilidad de aceptar la tesis dogmática, aparentemente incontrovertible, porque no encuentran proposiciones que sirvan de refutación o relativización en el momento en que se presenta el debate. Estas son las razones: i) es posible que sobre dicha tesis exista desacuerdo en algunos pueblos desconocidos para nosotros (EP, III, 233); ii) es posible que lo opuesto a la tesis ahora propuesta por ti exista realmente y aún no nos sea conocido; de modo que todavía no debemos dar nuestro asentimiento a esa tesis que de momento parece segura (EP, I, 34); iii) al igual que sucede con las cosas hechas por los prestidigitadores, que aunque los escépticos saben que hacen trampa no saben cómo la hacen; del mismo modo, tampoco se dejan persuadir por los razonamientos que, siendo falsos, parecen ser verídicos, incluso si ignoran en qué sentido se salen de la lógica (EP, II, 250); iv) hacen la analogía entre el camino y el precipicio con el argumento y el absurdo; si hubiera un camino que llevara a un precipicio, no se tirarían al precipicio por el hecho de haber un camino que conduce a él, sino que se apartan del camino a causa del precipicio: del mismo modo, aunque hubiera una argumentación que los llevara a algo reconocidamente absurdo, no asentirían al absurdo a causa de la argumentación, sino que se apartarían de la argumentación a causa del absurdo (EP, II, 252-253); es posible que sobre esa cosa exista desacuerdo en algunos pueblos desconocidos para nosotros (EP, III, 233). 
Incluir lo probable como posibilidad futura de encontrar un argumento que relativice la tesis expuesta por el dogmático, en primer lugar, denota, un problema de carácter, ya que al demostrársele con apremiantes argumentos que la tesis escéptica es contradictoria, y al no encontrar un contraargumento, lo que se espera es que ceda en su argumentación y acepte el otro punto de vista; así pues, con este argumento basado en lo probable nos indica que su carácter le impide comprender y aceptar lo que plantea el interlocutor; este es uno de los aspectos que trata Platón en Gorgias (493a y ss.), en el que se deduce que Calicles es incapaz de aceptar que se contradice, no por falta de inteligencia, sino por culpa de las limitaciones de su carácter; en palabras de Slezák, se muestra de la manera más expresiva que la conversación entre Sócrates y Calicles deja de ser una verdadera comunicación, porque Calicles no puede tratar al interlocutor con buena voluntad; Platón está convencido de que el verdadero filosofar solo es posible entre amigos, y que la argumentación filosófica solo puede ser fecunda si discurre en "discusiones bienintencionadas" (1991, p. 23). En segundo lugar, considero que contradice uno de los principios relacionados con las formas de expresión escéptica; en diferentes partes, Sexto Empírico subraya que nada de lo que afirman es como si fuera algo forzoso o necesario, sino que se expresan al modo de los historiadores, de acuerdo con lo que les resulta evidente en el momento actual (EP, I, 4; I, 15; I, 17). Aceptando como criterio lo manifiesto, afirman los pirrónicos que sencillamente se refieren a las cosas tal y como aparecen, en donde exponen sin dogmatismo su sentir; entonces, la cuestión radica en que no se atienen a este principio, lo evidente en el momento presente, cuando en los debates llegan a hacer proposiciones futuras acerca de situaciones probables para invalidar el otro argumento; estrategia argumentativa que podría ser caracterizada como erística, más que benévolas discusiones críticas (Carta VII, 344b), o donde se indaga acerca de la verdad del tema tratado en la medida en que se pueda conocer, como bien lo expresa Platón.

\section{Conclusiones}

En este ensayo se ha tratado acerca de lo novedoso y de la radicalidad de las estrategias argumentativas utilizadas por los escépticos pirrónicos, cuyo interés no es erístico ni antilógico, sino que tiene un componente práctico: suspender el juicio y lograr la serenidad del alma o paz espiritual (ataraxia), que surge como por azar.

Los pirrónicos hacen uso de diversas estrategias argumentativas con finalidad claramente terapéutica: curarnos de todo dogmatismo, y también son concordantes con la actitud zetética que los anima: investigar sin conocer el éxito de su indagación. 
La importancia de dichos argumentos recae en su uso, como medicina del alma, ya que de lo que se trata es de expulsar las creencias dogmáticas; lo paradójico es que también consideran que se expulsa el argumento utilizado. Además de afirmar que sus argumentos son utilizados como purgativos del alma, lo que pretenden mostrar los escépticos es que, al no ser posible conciliar dos o más posiciones o creencias establecidas en un dominio determinado, ya sea de la física, la lógica o la ética, esta situación de perplejidad nos lleva a optar por la suspensión del juicio.

Podemos afirmar, entonces, que la forma de argumentar escéptica terminó con la tradición agonística griega, generando una especie de ruptura con las formas tradicionales de argumentación filosófica, en la medida en que emplean sus argumentos no para convencer a los otros acerca de la verdad de sus creencias, y menos con el fin de señalar que son contradictorias, sino para indicar que no es más uno que el otro, que son equivalentes porque discurren paralelamente sobre el tema en cuestión.

Dentro de los aspectos problemáticos de la argumentación pirrónica se señalaron: 1) se asemeja a una dialéctica negativa, ya que no construyen ninguna teoría, sino que se limitan a desmontar lo que sostienen los otros filósofos o escuelas rivales, calificados de dogmáticos; 2) si bien son claros los propósitos tanto teóricos como práctico que los anima, el problema es cómo entender la persuasión en los escépticos, al igual que determinar si logran persuadir a los otros acerca del interés de tipo teórico que los lleva a argumentar; 3) no se puede hablar de discursos, sino de proposiciones opuestas o enfrentadas, en las que no se encuentran expuestas las razones o proposiciones que sirven de apoyo a una u otra tesis; 4) tal parece que la mayoría de las estrategias argumentativas utilizadas por los pirrónicos provienen de tropos que no son resúmenes de debates sostenidos por ellos, sino esquemas lógicos elaborados por Enesidemo y Agripa, cuya finalidad es conducir cualquier debate a la suspensión del juicio. Al no ser un resumen de un concurso ni de un debate en el que un árbitro o moderador expone el tema por discutir y dos oradores desarrollan las posiciones enfrentadas, como es el caso de los dobles razonamientos de los sofistas, se configura en una especie de monólogo que no pasa del nivel descriptivo al conversacional, en el que se observa que el escéptico expone las dos tesis y concluye en la necesidad de la epoché; 5) incluir lo probable como posibilidad futura de encontrar un argumento que relativice la tesis expuesta por el dogmático denota, en mi opinión, un problema de carácter, ya que al demostrársele con apremiantes argumentos que la tesis escéptica es contradictoria, y al no encontrar un contraargumento, lo que se espera es que ceda en su argumentación y acepte el otro punto de vista. 


\section{REFERENCIAS}

Aristóteles (1994). Metafísica. Madrid: Gredos. Introducción, traducción y notas de Tomás Calvo Martínez.

Bilbeny, N. (1998). Sócrates. El saber cómo ética. Barcelona: Península.

Bréhier, E. (1956). Historia de la filosofía. Tomo Primero. (Trad. Demetrio Náñez). Buenos Aires: Sudamericana.

Brisson, Luc. Sexta Parte. Las tradiciones platónicas y aristotélicas. En: CantoSperber, Monique. (2000). Filosofía griega. Vol. 2. La filosofía en la época helenística. Buenos Aires: Docencia.

Brochard, V. (1945). Los escépticos griegos. (Trad. Vicente Quinteros). Buenos Aires: Losada.

Calvo Martínez, T. (2008). Aristóteles y el aristotelismo. Madrid: Akal.

Chiesara, M. L. (2007). Historia del escepticismo griego. (Trad. Pedro Bádenas de la Peña). Madrid: Siruela.

Dueso, S. (2013). Los sofistas: Testimonios y fragmentos. Madrid: Alianza.

Empírico, S. (1993). Esbozos Pirrónicos. Madrid: Gredos. Introducción, traducción y notas de Antonio Gallego Cao y Teresa Muñoz Diego.

Empírico, S. (1997). Contra los profesores. Libros I-VI. Madrid: Gredos. Introducción, traducción y notas de Jorge Bergua Cavero.

Lloyd, G.E.R. Democracia, filosofía y ciencia en la antigua Grecia. En John Dunn (ed.) (1995). Democracia. El viaje inacabado (508 a.C.- 1993 d.C.). Barcelona: Tusques.

Nussbaum, M. (2003). La terapia del deseo. Teoría y práctica en la ética helenística. (Trad. Miguel Candel). Madrid: Paidós.

Platón (2005). Apología de Sócrates. Buenos Aires: Eudeba. Traducción, ensayo preliminar y notas de Conrado Eggers Lan.

Platón (2000). La República. Madrid: Alianza. Traducción de José Manuel Pabón y Manuel Fernández-Galiano. 
Platón (1985). Diálogos. Vol. I. Madrid: Gredos. [Protágoras. Traducción, introducción y notas de Carlos García Gual].

Slezák, Th. (1997). Leer a Platón. (Trad. José Luis García Rúa). Madrid: Alianza.

Vegetti, M. (2012). Quince lecciones sobre Platón. (Trad. Miguel Salazar). Madrid: Gredos. 